\title{
An Approach to Measuring Quality of Midwifery Care
}

\author{
T. A. Wiegers, ${ }^{1, *}$ M. J. N. C. Keirse, ${ }^{2}$ G. A. H. Berghs, ${ }^{1}$ and J. van der Zee ${ }^{1}$ \\ ${ }^{1}$ NETHERLANDS INSTITUTE OF PRIMARY health CARE (NIVEL), UTRECHT, \\ THE NETHERLANDS, AND 'DEPARTMENT OF OBSTETRICS, GYNECOLOGY, AND \\ REPRODUCTION, LEIDEN UNIVERSITY HOSPITAL, LEIDEN, THE NETHERLANDS
}

\begin{abstract}
In perinatology "Outcome" is almost always defined in terms of mortality or serious morbidity. Evaluation of care for normal pregnancy and midwifery care in particular cannot rely only on outcome measures per se, but must also take the means and interventions by which these are achieved into account. Perinatal Background and Perinatal Outcome Indexes were developed for the assessment of midwifery care in women with low-risk pregnancies. These indexes were applied in a prospective study of midwifery care during labor and childbirth for a population of 1836 women with low-risk pregnancies in The Netherlands. The Perinatal Background Index confirmed that the study population was indeed a population at low risk of perinatal complications. The Perinatal Outcome Index gave an adequate description of both the result and process of childbirth, with a lower score indicating a further deviation from the optimal situation of "maximum outcome with minimal intervention." $\mathrm{y}$ CLIN EPIDEMIOL 49;3:319-325, 1996.
\end{abstract}

KEY WORDS. Midwifery care, low-risk pregnancy, quality of care, perinatology, score systems, obstetrics

\section{INTRODUCTION}

Maternity care in The Netherlands is known for its high percentage of home births compared with other Western countries and for its organization with independent midwives, fully qualified to supervise uncomplicated pregnancies and childbirth. Both elements, place of birth and type of care provider, have never been without debate, with both issues often being entwined. The growing popularity of short-stay hospital births, also among midwives, and the attendant risk of increasing medicalization has introduced a new necessity for adequate evaluation of the professional performance of midwives and the significance of the place of birth for preserving their autonomy as care providers.

To understand the position of midwives in The Vetherlands it is necessary to give a brief outline of the organization of maternity care. Like the rest of Dutch health care, maternity care is divided into primary care and secondary care; the latter is accessible only after referral from a primary caregiver. The basic philosophy is that pregnancy and labor are fundamentally normal events that do not require disease-oriented medical care unless there are specific indications for it [1]. As long as the pregnancy is normal, materni y care is provided by a midwife or a general practitioner. In case of (threatening) pathology the woman is referred for specialist care. To guide this selection process a list of conditions has been constructed [2] for which referral for specialist advice or treatment is recommended. These conditions range from those that can negatively influence pregnancy and childbirth to those that are themselves negatively influenced by pregnancy. Referral for specialist care can occur at any moment during pregnancy, during labor, or after birth.

With the introduction, in the 1970s, of short-stay hospital births supervised by primary caregivers, midwives in particular, there has been increasing concern that this would lead to an increased referral for specialist care and, thence, undue intervention. Indeed, Damstra-

'Address for correspondence: Mrs. T. A. Wiegers, NIVEL, P.O. Box 1568, 3500 BN Utrecht, The Netherlands.

(Received in revised form 13 April 1995.)
$W_{\text {ijmenga }}[3,4]$ found higher referral rates among women choosing a short-stay hospital birth than among those choosing home birth, the largest increase being for "poor progress" in labor tesulting in a higher rate of instrumental delivery. Berghs and Spanjaards [5] reported higher intervention rates in women with low-risk pregnancies if care was given by obstetricians, rather than by midwives or general practitioners. Similar data were reported by Gerrits et al. [6] with respect to episiotomy rates.

There is likely to be general agreement that for any given outcome of pregnancy, this outcome should be achieved with a minimum of interference with natural processes and the woman's autonomy [7]. The pragmatic translation of such an agreement, however, is not without problems and this applies especially to low-risk pregnancies. Classic outcome measures, such as perinatal mortality and serious morbidity, have become too infrequent to be useful, particularly when applied to low-risk populations. Other outcome measures, such as Apgar score, birth weight, birth weight-by-gestational age, or preterm birth, address only one or two specific aspects of the condition of the baby instead of building a comprehensive picture that can serve as an overall evaluation of the situation.

Composite scores of adverse outcomes $[8,9]$ have been designed to address this problem, but the weighing of their individual components is not straightforward, their applicability to low-risk populations is limited, and they hardly ever consider interventionism as an integral part of what women themselves feel to be poor outcome. On the contrary, interventions during childbirth have, in formal risk scoring systems, often been regarded as risk markers to predict poor outcome, not as attributes of the outcome itself $[8,10]$.

We, therefore, developed a tool to measure "maximum outcome with minimal intervention" based on an optimality principle that was conceived in the late 1960 s for identifying a group of infants with a perfect start in life [11]. Basis for the optimality concept was that the mother should be in perfect health and that pregnancy and childbirth should have been devoid of even the slightest problem. It also entailed the assumption that any intervention in pregnancy and labor would be indicative of a problem and, thence, result in a child that failed to 
meet the "optimality" criterion $[12,13]$. This provided us with a list of items that could be adapted to assess midwifery care for low-risk women, taking into account not only perinatal outcome measures per se, but also the means by which these are achieved. We examined whether this adaptation could provide us with a useful tool for measuring the quality of midwifery care in low-risk pregnancies.

\section{MATERIALS AND METHODS Application of the Optimality Concept}

The merit of the optimality concept is that it avoids the problem of defining what is normal or abnormal by defining criteria in terms of the most favorable condition. An optimal situation is thus defined as a healthy woman without social, medical, or obstetrical problems giving birth, at the proper time without interventions or complications, to a healthy child.

$\Lambda$ list of obstetric and neonatal optimality criteria $[11,13]$ was constructed into a score simply by adding the number of optimal items. In developing this concept, it was argued that ". . . any non-optimal obstetrical variable of serious clinical significance is accompanied by a number of other non-optimal findings. The system is therefore selfweighting, a further gradation of non-optimality per obstetrical variable is not necessary, and the pitfall of the distinction between more or less 'dangerous' complications is avoided." [13]. The self-weighting capacity of this scoring system was confirmed in Swedish research [14] and the scores were found to relate significantly to neurological findings in the infants [13].

The optimality score [13] consisted of 74 items divided in 7 categories and was based on a cohort of 3162 singleton infants born between 1975 and 1978 in Groningen University Hospital (Groningen, The Netherlands). A Cronbach $\alpha$ or reliability coefficient was calculated for each category with the following findings [13]:

\begin{tabular}{ll}
\hline Category & $\alpha$ \\
\hline 1. Social background (13 items) & 0.43 \\
2. Nonobstetrical conditions during pregnancy (9 items) & 0.02 \\
3. Obstetrical past history (14 items) & 0.18 \\
4. Obstetrical aspects of present pregnancy (11 items) & 0.27 \\
5. Diagnostic and therapeutic measures (8 items) & 0.41 \\
6. Parturition (11 items) & 0.42 \\
7. Neonatal condition immediately after birth (8 items) & 0.64 \\
\hline
\end{tabular}

The reliability coefficient $\alpha$ was considered satisfactory if higher than 0.40 and it was argued that the low internal consistency, found in three of the categories, was due to low, or even negative, interitem relationships within these categories, caused by obvious heterogeneity of the items. Refinement of the list was therefore recommended [13].

However, Cronbach's $\alpha$ (or KR-20 for dichotomous scores) is a summary statistic based on variances and covariances of the scores on individual items within each category. The value depends on the average interitem correlation and the number of items in the scale $[15,16]$. The value of $\alpha$ increases as the average correlation among items and the number of items increase. This is, however, a psychometric approach to an essentially clinimetric index, of which the multiple items are not expected to be homogeneous because they indicate different attributes of a complex phenomenon [16]. The Apgar score is a good example of a clinimetric index of five different attributes (heart rate, respiratory rate, color, muscle tone, reflex response) with high intraand interclinician reliability, although it is not expected to be homoge- neous $[16,17]$. In the same way the obstetric optimality scorc should be regarded as a clinimetric index, containing a number of different attributes relevant to obstetrical status. More important than internal consistency is the content validity of a clinimetric index. Content validity cannot be demonstrated with statistical tests, but is based on agreement among clinicians about inclusion of the most important components.

A subdivision of the optimality score was later devised by Berghs and Spanjaards [5]. They divided the score in three parts dealing with background of the woman and pregnancy (47 items), with birth (11 items), and with the newborn ( 7 items). They applied the score for a detailed description of low-risk pregnancies and births, finding only a weak relation between perinatal factors in the score and the neurological condition of the infants.

For assessing the quality of midwifery care we adapted the score in two ways. First, items were considered in the light of current day practice resulting in, for instance, a changed optimal value for perineal laceration from "episiotomy" to "none" and adding an episiotomy item with optimal value "no." Second, the score as such was divided in two parts: items that relate to characteristics present before the onset of labor and those that evolved during labor and thereafter. This resulted in a Perinatal Background Index (original categories 1, 2, 3, 4, and 5; combined, 31 items) and a Perinatal Outcome Index (original categories 6 and 7 plus an added category for the condition of the mother in the week after delivery; combined, 36 items).

\section{Participants}

A prospective study among women with low-risk pregnancies was carried out in Gelderland, 1 of 12 provinces in The Netherlands, during 2 periods in the years 1990-1992. Only women receiving antenatal care exclusively from a midwife, up to the onset of labor were eligible for participation. Thus, women who had been referred for specialist care before the onset of labor were excluded, but not those referred during labor or after delivery.

A sample of 2301 women, stratified according to the intended place of birth, signed informed consent forms and received a questionnaire, to be completed approximately 4 weeks before the expected date of birth, asking about their social, medical, and obstetric background and their preferences for home or hospital birth. The midwives caring for them also received questionnaires, one to be completed before and one after each birth. A copy of the formal birth notification by the midwife, with data on delivery itself, including relevant medical and obstetric background information, was added to the completed questionnaires. Of the 2130 women for whom a birth notification was received, 294 had been referred to an obstetrician before the onset of labor and they were excluded from the study. This reduced the study population to 1836 women, 840 primiparae and 996 multiparae, for whom a birth notification was available. Of them, 1720 (93.7\%) had returned the questionnaire with information on background and preference.

Outcome data and obsterric background data were derived from the birth notifications and the questionnaires filled out by the midwives. Other social and medical information was derived from the questionnaires of the women and the midwives. Cases with missing data on the background variables, including 116 unreturned questionnaires, were excluded from the appropriate analyses, while the less than $2 \%$ missing data on outcome variables (unchecked boxes on the forms) were considered to have been optimal. The latter option was chosen after verification in a large subset, including all missing data on birth weight and perinatal death, that unchecked boxes indicated that ab- 


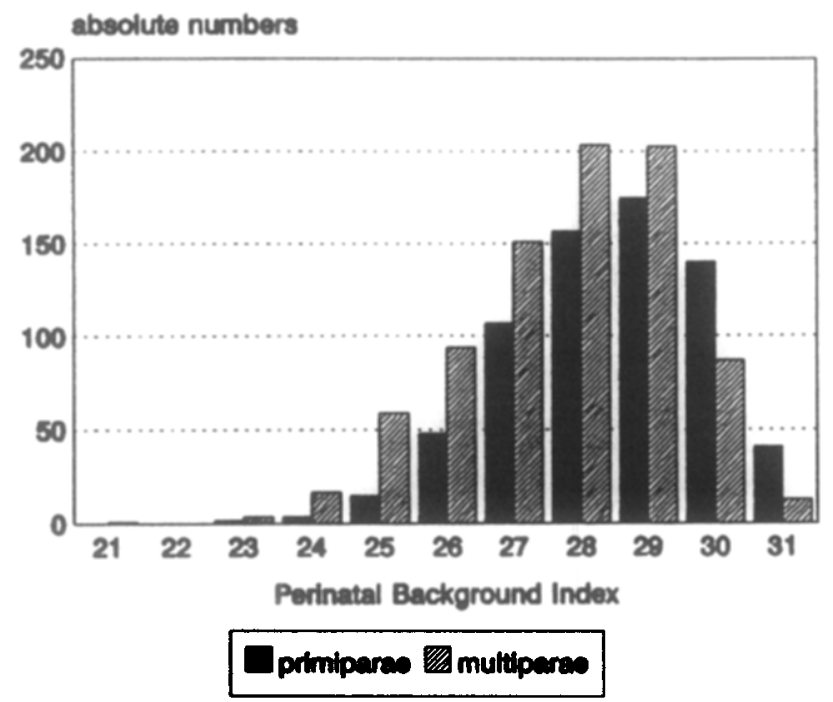

FIGURE 1. Frequency distribution of the Perinatal Background Index with 31 items (maximum score $=31$ ) in a low-risk population, for primiparae $(n=689)$ and multiparae $(n=833)$ separately.

normalities in this respect had been evidently absent. Appendices 1 and 2 show all variables used in the indexes with their criteria for optimality, the frequency of optimality, and the number of missing data that led to exclusion.

\section{RESULTS}

The distribution of the Perinatal Background Index is shown in Fig. 1. The median for the entire population ( 1522 valid cases, 314 missing) is found at score 28 with a skewness of -0.50 and a range of 21 to 31 . Separate values for primiparae (689 valid cases, 151 missing) are 29, -0.48 , and 23 to 31 ; for multiparae (833 valid cases, 163 missing) the values are $28,-0.51$, and 21 to 31 . The $10 \mathrm{th}, 25 \mathrm{th}, 75 \mathrm{th}$, and 90 th centiles hardly differed with parity being at scores $26,27,30$, and 30 for primiparae and $26,27,29$, and 30 for multiparae. Only 54 women $(3.5 \%), 41$ primiparae $(6.0 \%)$ and 13 multiparae $(1.6 \%)$, scored optimal on all background variables. Some variables relating to medical or obstetric history come very close to $100 \%$ optimality (Appendix 1), which implies that they either occur rarely or result in referral for specialist care during pregnancy, effectively withdrawing these women from the study.

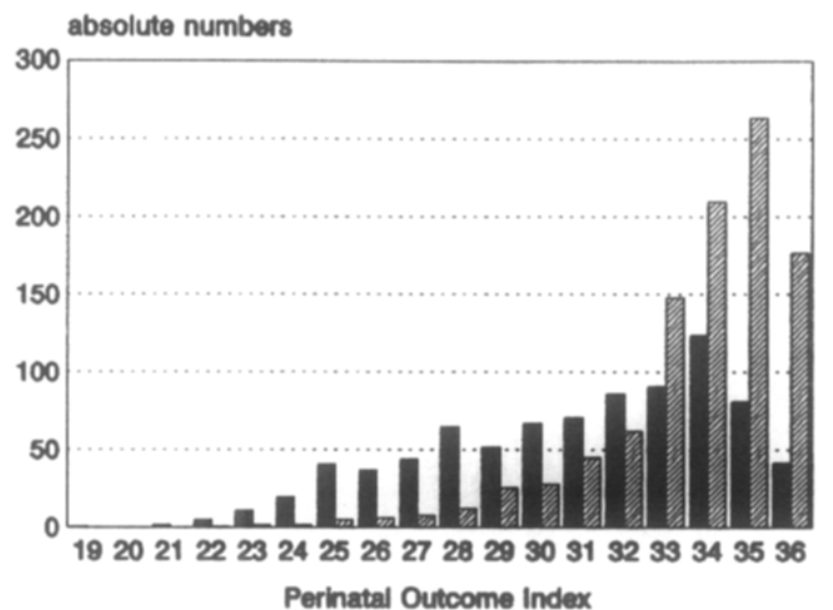

primipares $\mathbb{Z}$ multipares

FIGURE 2. Frequency distribution of the Perinatal Outcome Index with 36 items (maximum score $=36$ ) in a low-risk population, for primiparae $(n=840)$ and multiparae $(n=996)$ separately.

Consistency analysis showed a Cronbach $\alpha$ of 0.29 for the Perinatal Background Index, with coefficients for the subcategories (Table 1) that are comparable to those reported by Touwen et al. [13]. This indicates a low internal consistency, reflecting the heterogeneity of the background items. The mean scores and their $95 \%$ confidence intervals (Table 1) show the high proportion of optimal items in each category, which also attributes to a lower $\alpha$ value.

The distribution of the Perinatal Outcome Index is shown in Fig. 2. The median for the entire population ( 1836 valid cases, none missing) was at score 33 , with a skewness of -1.12 and a range of 19 to 36. These figures are as follows: for primiparae ( 840 cases), $32,-0.56$, and 19 to 36; for multiparae (996 cases), 34, -1.72 , and 22 to 36 . The 10th, 25th, 75th, and 90th centiles showed more difference with parity than the Perinatal Background Index, being 26, 28, 34, and 35 for primiparae and $31,33,35$, and 36 for multiparae. An optimal score (219 women; $11.9 \%$ ) occurred four times as often among multiparae $(n$ $=177,17.8 \%)$ than among primiparae $(n=42,5.0 \%)$. As a group, only the variables relating to the condition of the mother postpartum came close to $100 \%$ optimality (Appendix 2 ).

Consistency analysis showed a Cronbach $\alpha$ value of 0.78 for the Perinatal Outcome Index (see Table 1). Although the category "condi-

TABLE 1. Categories of the Perinatal Background Index and the Perinatal Outcome Index

\begin{tabular}{|c|c|c|c|c|}
\hline Categories & $\begin{array}{l}\text { No. of } \\
\text { items }\end{array}$ & Mean & $95 \% \mathrm{CI}$ & Cronbach $\alpha$ \\
\hline \multicolumn{5}{|l|}{ Perinatal Background Index } \\
\hline Social and medical background & 9 & 7.72 & $7.67-7.77$ & 0.17 \\
\hline Past obstetric history & 10 & 9.92 & $9.91-9.94$ & 0.12 \\
\hline Present pregnancy, diagnostic and therapeutic measures & $\underline{12}$ & 10.40 & $10.35-10.46$ & 0.30 \\
\hline Perinatal Background Index: & $\overline{31}$ & 28.07 & $27.99-28.15$ & 0.29 \\
\hline \multicolumn{5}{|l|}{ Perinatal Outcome Index } \\
\hline Parturition & 22 & 18.99 & $18.87-19.11$ & 0.76 \\
\hline Neonatal condition & 9 & 8.42 & $8.38-8.47$ & 0.50 \\
\hline \multirow[t]{2}{*}{ Condition of the mother after birth } & 5 & 4.99 & $4.96-5.00$ & -0.01 \\
\hline & $\overline{36}$ & 32.40 & $32.26-32.55$ & 0.78 \\
\hline
\end{tabular}


TABLE 2. Correlations between separate categories of the Perinatal Background Index, the Perinatal Background Index itself, and the Perinatal Outcome Index for primiparae and multiparae separately

\begin{tabular}{lllc}
\hline Primiparae $(\mathrm{N}=\mathbf{6 8 9})$ & $\begin{array}{c}\text { Perinatal } \\
\text { Outcome } \\
\text { Index }\end{array}$ & Multiparae $(\mathrm{N}=\mathbf{8 3 3})$ & $\begin{array}{c}\text { Perinatal } \\
\text { Outcome } \\
\text { Index }\end{array}$ \\
\hline Social and medical background & 0.06 & Social and medical background & 0.03 \\
Obstetric past history & 0.04 & Obstetric past history & 0.08 \\
Present pregnancy & 0.08 & Present pregnancy & $0.12^{*}$ \\
Perinatal Background Index & $\mathbf{0 . 1 0 ^ { * }}$ & Perinatal Background Index & $\mathbf{0 . 1 2 *}$ \\
\hline P & & &
\end{tabular}

$* p<0.001$.

tion of the mother after birth" adds hardly anything to the index, its removal means the loss of some, albeit little, information, while it would not increase the overall coefficient of the index. The internal consistency of the Perinatal Outcome Index indicates that it is not without merit as a scale instrument.

When relating the Perinatal Background Index and its components to the Perinatal Outcome Index, it is clear that the relationship is exceedingly poor even if the overall correlations reach statistical significance (Table 2). This indicates that women with serious nonoptimal items in the Perinatal Background Index that could have influenced perinatal outcome and thus the scores on the Perinatal Outcome Index were probably removed effectively from the study population. It also indicates that the remaining nonoptimality in the Perinatal Background Index has little bearing on the final Perinatal Outcome Index, which includes not only maternal and neonatal outcomes per se, but also the range of interventions that was applied to achieve them. This is exemplified by comparing women with scores of the Perinatal Background Index above and below the nedian in terns of a relatively low score on the Perinatal Outcome Index, defined as a score below the 25 th centile. Table 3 shows the proportion of women with a low score on the Perinatal Background Index in this approach for both primiparae and multiparae to be $23 \%$, still below the 25 th centile. The corresponding values for sensitivity and specificity are, respectively, 0.60 and 0.53 for primiparae and 0.48 and 0.64 for multiparae.

\section{DISCUSSION}

In this study we have examined Perinatal Background and Perinatal Outcome Indexes, based on the Prechtl optimality concept, in terms of their usefulness for measuring the quality of midwifery care. The optimality concept was chosen to develop these instruments for two reasons. First, it avoids the problem of defining what is normal and what is pathological, by defining (sometimes narrow) ranges of optimal values $[12,13]$. Second, in a population consisting only of women without known risk factors for complications in pregnancy or childbirth, few serious adverse outcomes are expected. Therefore, an instrument is needed that also includes moderately adverse outcome measures. Several scoring systems have been developed in earlier research, but most of these concentrate on antepartum and/or intrapartum risk assessment in relation to one or two specific outcome measures, such as preterm birth or low birth weight [18-23]. The average predictive value of these scores is low, which is not uncommon for screening instruments $[18,20,22,23]$.

The instruments presented here are based on the two distinct aspects of midwifery care. The first relates to antenatal care with careful monitoring of the course of pregnancy in order to ensure a normal development or to identify possible risks that might endanger mother or fetus. The second relates to intrapartum and postpartum care for those mothers who have been identified as still being at low risk. Our Perinatal Background Index reflects the social, medical, and obstetric status of

TABLE 3. Frequencies (and row percentages) of high and low (below the median) scores on the Perinatal Background Index, for women with high and low (below 25 th centile) scores on the Perinatal Outcome Index, for primiparae and multiparae separately

\begin{tabular}{|c|c|c|c|c|c|c|}
\hline \multirow[b]{2}{*}{ Parity } & & \multicolumn{2}{|c|}{$\begin{array}{l}\text { High score on the Perinatal } \\
\text { Outcome Index }\end{array}$} & \multicolumn{2}{|c|}{$\begin{array}{c}\text { Low score on the Perinatal } \\
\text { Outcome Index } \\
\end{array}$} & \multirow{2}{*}{$\begin{array}{l}\text { Total } \\
\text { No. }\end{array}$} \\
\hline & & No. & $\%$ & No. & $\%$ & \\
\hline \multicolumn{7}{|l|}{ Primiparae } \\
\hline $\begin{array}{l}\text { High score on the Perinatal } \\
\text { Background Index }\end{array}$ & & 305 & 85.7 & 51 & 14.3 & 356 \\
\hline \multirow[t]{2}{*}{$\begin{array}{l}\text { Low score on the Perinatal } \\
\text { Background Index }\end{array}$} & & $\underline{256}$ & 76.9 & 77 & 23.1 & 333 \\
\hline & Total: & : 561 & 81.4 & 128 & 18.6 & 689 \\
\hline $\begin{array}{l}\text { Multiparae } \\
\text { High score on the Perinatal } \\
\text { Background Index }\end{array}$ & & 424 & 83.6 & 83 & 16.4 & 507 \\
\hline \multirow{2}{*}{$\begin{array}{l}\text { Low score on the Perinatal } \\
\text { Background Index }\end{array}$} & & $\underline{251}$ & 77.0 & 75 & 23.0 & $\underline{326}$ \\
\hline & Total: & $: 675$ & 81.0 & 158 & 19.0 & 833 \\
\hline
\end{tabular}


the woman up to the onset of labor. The background is defined as a list of items that are thought to relate, directly or indirectly, to obstetric outcome, but are not necessarily related to each other. For some of the background items, such as smoking and body mass index, the relation with pregnancy outcome is well known [24-27]; for other items the relation is more obscure and intermediate. But the expected relation is always in the same direction: any nonoptimal item in the Perinatal Background Index will have a negative or at best no effect on the obstetric result.

The proportion of women with a value below the median on the Perinatal Background Index in terms of a relatively poor outcome is shown to be low, indicating that this entire study population is indeed a low-risk population. The fact that we found no clear relation between the Perinatal Background Index and the Perinatal Outcome Index indicates that women at risk for complications and women with a number of nonoptimal background characteristics that by themselves are not considered to be risk factors, but can in combination lead to a changed risk status, are effectively removed from the study population before the onset of labor. This testifies to the quality of the selection process of the midwife during antenatal care. To assess the quality of antenatal care, however, it is not enough to show that women with risk factors are effectively removed from the low-risk population by referral to specialist care. We should also be able to determine whether referral was effectuated for only those women who would benefit from specialist care. In other words, we need to know whether criteria for referral are not set too low, resulting in a higher referral rate than would be necessary. With our data we cannot evaluate this aspect of antenatal midwifery care.

In a low-risk population, childbirth is expected to follow its natural course without the need for medical intervention. Unnecessary intervention, including restricting the woman's autonomy, is regarded as an integral part of poor outcome [7]. This means that assessing the quality of intrapartum care for low-risk women should take into account not only the well-known outcome measures, such as mortality, morbidity, low Apgar scores, or low birth weight, but also the process aspects of care, that is, the means by which the outcome is achieved. The Perinatal Outcome Index we presented in this article is a combination of process and outcome measures, reflecting this philosophy. The interrelation between means and results, interventions and outcome of care, is demonstrated by the high internal consistency of the index. In our view this Perinatal Outcome Index gives, first of all, an accurate description of what happened during and after childbirth. Mureuver, it reflects the seriousness of complications by combining interventions and poor outcome measures, thereby showing some self-weighing capabilities. A lower Perinatal Outcome Index indicates a further regression from the optimal situation, that is, a birth without complications or interventions occurring at the proper time and resulting in a healthy baby and a healthy mother. Because there is no "gold standard" for obstetric result other than the well-being of mother and child, we defined arbitrarily the lowest $25 \%$ of the Perinatal Outcome Index as "less than good." We did not find a meaningful association with the Perinatal Background Index, indicating that the nonoptimal items present in the mother's background cannot be regarded as "risks" for adverse outcome.

We conclude that the Perinatal Outcome Index gives a reliable picture of the known differences between primiparous and multiparous women and is detailed enough to differentiate between subgroups of women with low-risk pregnancies. Especially in a low-risk population a detailed result score is needed to reflect the differences that could result from different policies in obstetric care. Berghs and Spanjaards [5] demonstrated, with the help of the optimality concept, the differ- ences between midwives, general practitioners and obstetricians in guiding the childbirth of women with low-risk pregnancies. They found the lowest intervention rate in births supervised by midwives. With the Perinatal Background Index we confirmed the low-risk status of our study population, but in part because of it, we cannot comment on its assumed self-weighing capacity.

In our view, both indexes are potentially useful tools for assessing the quality of midwifery care. They are, however, not to be regarded as static instruments. Their internal validity should be closely monitored and, if necessary, adapted to changed insights in obstetric and maternity care. Moreover, not all information we used in developing these indexes is incorporated in standard registration procedures, such as the formal birth notification. Some of the information about the social background was derived from the women's questionnaires; some information about antenatal care was derived from the midwives' questionnaires. To be able to use both indexes in quality assurance programs those items would need to be added to the standard registration forms.

This study was supported by a grant from "Het Praeventiefonds" (the Prevention Fund) No. 28-1644.

\section{References}

1. Treffers $P E$, Eskes $M$, Kleiverda $G$, van Alten D. Home births and minimal medical interventions. JAMA 1990; 264: 2203-2208.

2. Ziekenfondsraad. Verloskundige Indicatielijst 1987 (Final report of the working party to adjust the Kloostermanlijst). Ziekenfondsraad. Amstelveen, 1987.

3. Damstra-Wijmenga SMI. Veilig Bevallen. Een Vergelijkende Studie tussen de Thuisbevalling en de Klinische Bevalling. Ph.D thesis, Groningen University, Groningen, The Netherlands, 1982.

4. Damstra-Wijmenga SMI. Home confinement: The positive results in Holland. J R Coll Gen Pract 1984; 256: 425-430.

5. Berghs G, Spanjaards E. De Normale Zwangerschap; Bevalling en Beleid. Ph.D. thesis, Nijmegen University, Nijmegen, The Netherlands, 1988.

6. Gerrits DD, Brand R, Bennebroek Gravenhorst J. The use of an episiotomy in relation to the professional education of the delivery attendant. Eur J Obstet Gynecol Reprod Biol 1994: 56: 103-106.

7. Enkin M, Keirse MJNC, Renfrew M, Neilson I. A Guide to Effective Care in Pregnancy and Childbirth. Oxford University Press, Oxford, 1995, p. 389.

8. Hobel CJ, Hyvarinen M, Okada DM, Oh W. Prenatal and intrapartum high-risk screening. I. Prediction of the high-risk neonate. Am J Obstet Gynecol 1973; 117: 1-9.

9. LeFevre M, Williamson HA, Hector M. Obstetric risk assessment in rural practice. J Fam Practice 1989; 28: 691-696.

10. Molfese VJ, Thomson BK, Bennet AG. Perinatal outcome. Similarity and predictive value of antepartum and intrapartum assessment scales. J Reprod Med 1985; 30: 30-38.

11. Prechtl HFR. Neurological findings in newbom infants after pre- and paranatal complications. In: Aspects of Prematurity and Dysmaturity (Jonxis JHP, Visser HKA, Troelstra JA, eds.). Stenfert Kroese, Leiden, 1968, pp. 303-321.

12. Prechtl HFR. The optimality concept (editorial). Early Hum Dev 1980; 4: $201-205$.

13. Touwen BCL, Huisjes HJ, Jurgens-van der Zee AD, Bierman-van Eendenburg MEC, Smrkovsky M, Olinga AA. Obstetrical condition and neonatal neurological morbidity. An analysis with the help of the optimality concept. Early Hum Dev 1980; 4: 207-228.

14. Kylletman M, Hagberg G. Reduced optimality in pre- and perinatal conditions in a Swedish newborn population. Neuropediatrics 1983; 14: 37-42.

15. Carmines EG, Zeller RA. Reliability and Validity Assessment. Sage University Papers. Sage Publications, Beverly Hills/London, 1979

16. Wright JG, Feinstein AR. A comparative contrast of clinimetric and psychometric methods for constructing indexes and rating Scales. J Clin Epidemiol 1992; 45: 1201-1218.

17. Schmidt B, Kirpalani H, Rosenbaum P, Cadman D. Strengths and limitations of the Apgar score: A critical appraisal. J Clin Epidemiol 1988; 41 : 843-850.

18. Alexander S, Keirse MJNC. Formal risk scoring during pregnancy. In: 
Effective Care in Pregnancy and Childbirth (Chalmers I, Enkin M, Keirse MJNC, eds.), Vol. 2. Oxford University Press, Oxford, 1989, pp. $345-365$.

19. Edwards LE, Barrada I, Tatreau RW, Hakanson EY. A simplificd antepartum risk-scoring system. Obstet Gynecol 1979; 54: 237-240.

20. Keirse MJNC. An evaluation of formal risk scoring for preterm birth. Am J Perinatol 1989; 6: 226-233.

21. Pecorari D, Romanini C, Tanganelli E. Score systems in perinatal medicine. Biol Res Pregnancy 1985; 6: 101-111.

22. Wall EM. Assessing obstetric risk. A review of obstetric risk-scoring systems. J Fam Practice 1988; 27: 153-163.

23. Wall EM, Sinclair AE, Nelson I, Toffler WL. The relationship between assessed obstetric risk and maternal-perinatal outcome. J Fam Practice $1989 ; 28: 35-40$.
24. Kleinman JC, Madans JH. The effects of maternal smoking, physical stature and educational attainment on the incidence of low birthweight. Am J Epidemiol 1985; 121: 843-855.

25. McCormick MC, Brooks-Gunn J, Shorter T, Holmes JH, Wallace CY, Heagarty MC. Factors associated with smoking in low-income pregnant women: Relationship to birth weight, stressful life events, social support, health behaviours and mental distress. J Clin Epidemiol 1990; 43: 441-448.

26. Garbaciak JA, Richter M, Miller S, Barton JJ. Maternal weight and preg. nancy complications. Am J Obstet Gynecol 1985; 152: 238-245.

27. Varma TR. Maternal weight and weight gain in pregnancy and obstetric outcome. Int J Gynaecol Obstet 1984; 22: 161-166.

APPENDIX 1. The 31 Items of the Perinatal Background Index ${ }^{2}$

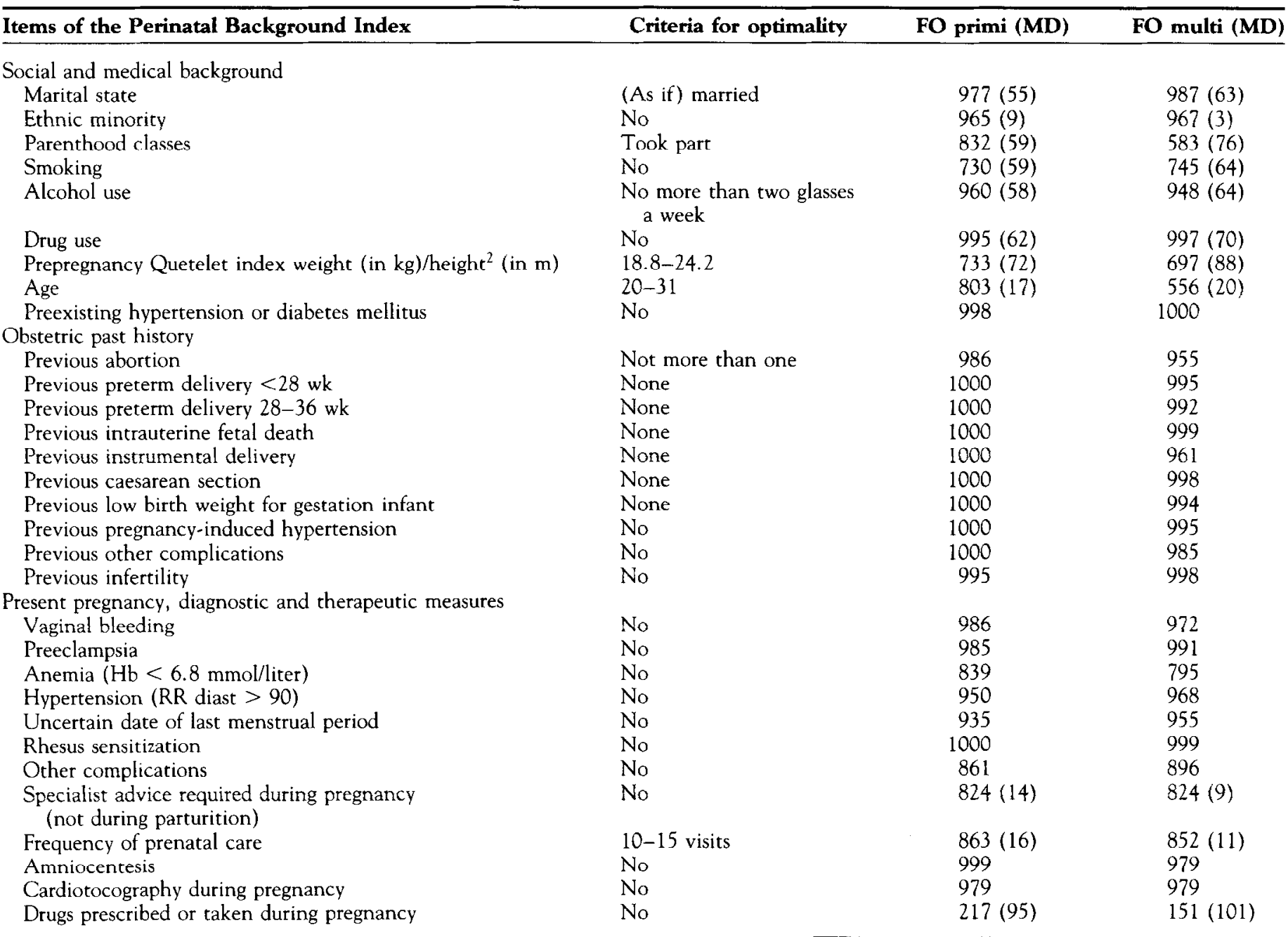

Abbreviations: $\mathrm{Hb}=$ hemoglobin; $\mathrm{RR}$ diast $=$ diastolic blood pressure.

"Criteria for optimality are in the second column. Missing data (MD) from the questionnaires are excluded from the analyses. Third and fourth columns show the frequency of optimality (FO) per thousand cases for primiparae and multiparae separately (missing data [MD] in absolute numbers). 
APPENDIX 2. The 36 ltems of the Perinatal Outcome Index ${ }^{a}$

Items of the Perinatal Outcome Index

Parturition

Medication during first stage of labor

Time between rupture of membranes and birth

Amniotic fluid

Duration first stage

Duration second stage

Presentation at birth

Assisted delivery (not instrumental)

Perineal laceration

Episiotomy

Referral during labor

Insufficient cervical dilatation

Insufficient progress in second stage

Fetal distress

Induction/augmentation of labor

Instrumental (vaginal) delivery

Caesarean section

Suturing (total) perineal tear

Medication during the third stage of labor

Placental retention

Loss of blood during delivery

Blood transfusion

Other problems

Neonatal condition

Birth weight

Apgar score at $5 \mathrm{~min}$

Perinatal death

Transfer to neonatal ward

Congenital anomalies

Birth trauma

Problems in first $24 \mathrm{hr}$

Problems in first wcek

Duration of gestation

Condition of the mother after birth

Mastitis

Endometritis

Cystitis

Medication in puerperium

Other problems
Criteria for optimality

FO primi

FO multi

None $\quad 777$

$\leq 12 \mathrm{hr} \quad 842$

Clear $\quad 848$

$\leq 10 \mathrm{hr} \quad 762$

$\leq 60 \mathrm{~min}$

Cephalic 960

No $\quad 704$

No $\quad 232$

No $\quad 474$

No $\quad 615$

No 910

No $\quad 890$

No 954

No

No $\quad 854$

No $\quad 965$

No $\quad 986$

No 371

No

$<1000 \mathrm{ml}$

No $\quad 990$

None $\quad 858$

p10-p90

$\geq 9$

No

No

No

No

No

No

37-42 weeks

No

No

No

No

No
930

933

868

954

985

981

951

444

811

900

985

993

993

980

988

997

994

555

986

984

994

933

$826 \quad 826$

$920 \quad 958$

998

$862 \quad 948$

$981-981$

994

$794+934$

$931-972$

$950 \quad 958$

$1000 \quad 999$

$998 \quad 999$

$1000 \quad 998$

$1000 \quad 997$

$996 \quad 998$

${ }^{a}$ Criteria for optimality are shown in the second column and the frequency of optimality (FO) per thousand cases for primiparae and multiparae separately in the last two columns. 